\title{
Drain amylase levels may indicate gastrojejunostomy leaks after Roux-en-Y gastric bypass
}

\author{
Igor Braga RIBEIRO, Martinho Antonio GESTIC, Murillo Pimentel UTRINI, \\ Felipe David Mendonça CHAIM, Elinton Adami CHAIM and Everton CAZZO
}

\begin{abstract}
Background - Although the incidence of leaks after Roux-en-Y gastric bypass (RYGB) significantly decreased over time, their detection still remains challenging. Objective - This study aimed to determine the usefulness of drain amylase levels to detect leaks after RYGB. Methods - This is a population-based study which enrolled 170 individuals who underwent RYGB. Drain amylase levels were determined on the first and fourth postoperative days. Two thresholds were evaluated: three times higher than the serum levels (parameter I) and higher than 250 IU/L (parameter II). The main outcomes evaluated were perioperative morbidity, the occurrence of leaks, 30-day readmissions and reoperations, hospital stay, and mortality. Results - Considering the parameter I, high drain amylase levels were significantly associated with leaks $(12.5 \%$ vs $0 ; P<0.00001)$. Considering the parameter II, high drain amylase levels were significantly associated with longer hospital stay ( $8 \pm 5.7$ vs $4.5 \pm 1.3$ days; $P=0.00032$ ), 30 -day reoperations ( $50 \%$ vs $3 \% ; P=0.000285$ ), and leaks ( $50 \%$ vs $0 ; P<0.00001)$. The parameter I presented a sensitivity of $100 \%$ and specificity of $95.9 \%$, whereas the parameter II presented a sensitivity of $100 \%$ and a specificity of $99.4 \%$. Conclusion - The determination of drain amylase levels after RYGB was a significant indicator of leaks, hospital stay, and 30-day reoperations. This finding reinforces the importance of abdominal drainage in the RYGB within this context. HEADINGS - Obesity. Bariatric surgery. Gastric bypass. Anastomotic leak. Postoperative complications.
\end{abstract}

\section{INTRODUCTION}

In the context of the obesity epidemics ${ }^{(1,2,3)}$, despite its efficacy and excellent outcomes for the treatment of refractory morbid obesity, at both weight loss and resolution of comorbidities ${ }^{(4,5,6,7)}$, Roux-en-Y gastric bypass (RYGB) also presents the risk of ominous postoperative complications. The incidence of major morbidity following RYGB has significantly decreased over the years, especially due to the evolution of the technique, increasing surgical skills of bariatric surgical teams, and the improvement in the postoperative care ${ }^{(8)}$. Anastomotic leaks are among the most feared complications, since they are likely to account for up to $30 \%$ of all perioperative mortality after $\mathrm{RYGB}^{(8,9)}$. Although the incidence of leaks significantly decreased over time, their detection still remains challenging. Since an early diagnosis is a key point to the rate of treatment success in this scenario, the development of easily available and inexpensive tools to detect postoperative leaks represents a significant issue.

This study aimed to determine the usefulness of the determination of the amylase levels in the abdominal drainage of individuals which underwent RYGB to detect gastrointestinal leaks and to indicate postoperative morbidity and mortality.

\section{METHODS}

This is a population-based study carried out though the prospectively collected database of a bariatric surgery service of a public tertiary university hospital. This study underwent evaluation and was approved by the local Ethics Review Board under the reference number Unicamp/1.847.467 (CAAE: 61533316.9.0000.5404).

The inclusion criteria were: 1) individuals with morbid obesity who underwent RYGB; 2) both sexes; 3) 18 to 70 years old. The exclusion criteria were: 1) actual or previous pancreatic diseases; 2) actual or previous parotid diseases; 3 ) macroamylasemia; 4) actual or previous use of alcohol and illicit drugs; 5) abnormal renal function. Pancreatic and parotid diseases were assessed by means of previous medical records or positive history or antecedents declared by the individuals. Macroamylasemia was assessed by means of clinical history and serum amylase levels; when there were high amylase levels without any other cause, the individual was excluded and referred to the clinical gastroenterology service for additional investigation. Surgery was indicated based on the National Institutes of Health Consensus Statement criteria ${ }^{(10)}$. Estimation of sample size was performed using single proportion formula with $95 \%$ confidence interval; precision was set at $5 \%$ and the calculated sample size was 132 . Of 189 individuals who underwent RYGB from January 2015 through August 2016, 170 were selected for study. Twelve individuals were excluded due to a previous significant use of alcohol, three presented abnormal renal function tests, two presented a recent episode of acute biliary pancreatitis, one presented mumps in the last year, and one presented with macroamylasemia. 
Both serum amylase and drain amylase levels were determined by means of an enzymatic assay and was expressed in international units per liter (IU/L). The serum levels considered normal in this method range from 10 to $110 \mathrm{IU} / \mathrm{L}$. Blood samples to determine the serum amylase levels were collected on the day of surgery, and on the first and fourth postoperative days. The levels of amylase in the abdominal drain were determined on the first and fourth postoperative days. Since there are no validated cutoff values for this examination, we evaluated two previously reported cutoff values: three times higher than the serum levels and higher than 250 IU/L ${ }^{(11)}$. The individuals were divided into two groups depending on the drain amylase levels; we considered the "case" group those who presented high levels, according to the threshold utilized, and the "control" group those who presented lower levels. Since there was no current protocol on how to apply these levels in the postoperative management during the course of the present study, neither universally accepted cut-off values, the drain amylase levels did not influence the management of the patients.

The variables analyzed were: age, gender, weight, body mass index (BMI), operative time, estimated intraoperative bleeding, hospital stay, 30-day overall morbidity, 30-day hospital readmissions, and 30-day mortality. The primary outcome was the occurrence of leaks, and the secondary outcomes were mortality, overall morbidity, reoperations, hospital stay, and 30-day readmissions. The considered exposure variable was the amylase levels in the drain.

All procedures were performed by the same surgical team and with the same technique. The main features of the RYGB were a $30-\mathrm{mL}$ gastric pouch, a $100-\mathrm{cm}$ biliopancreatic limb, a $150-\mathrm{cm}$ alimentary limb, and a common limb consisting of the remainder of the small intestine. All individuals had their cavities drained by means of a silicon vacuum drain $\left(\mathrm{J}-\mathrm{Vac}^{\circledR}\right)$, located nearby the gastrojejunostomy. In the operative protocol of our service, a drain is placed in all the procedures. All individuals underwent a pouch and gastrojejunostomy evaluation before discharge on the fourth postoperative day by means of an upper gastrointestinal series and an oral methylene blue solution diluted in filtered water challenge. The postoperative protocol of this service includes a standardized 4-day hospital stay.

The occurrence of a leak was determined by the presence of clinical suggestive signs (tachycardia, fever, hypotension a/ or abdominal pain) associated with confirmation by means of tomographic and/or intraoperative findings. Whenever a leak is suspected, an immediate surgical exploration is warranted. During the surgical intervention, the leaks were identified by means of direct visualization whenever it was possible, or by means of methylene blue infusion through a Foucher tube introduced during the intervention under direct visualization. To assess the diagnostic accuracy of a test for detection of leaks, the presence of clinical suggestive signs (tachycardia, fever, hypotension a/or abdominal pain) associated with a confirmation by means of tomographic and/or intraoperative findings was considered the gold-standard.

\section{Statistical analysis}

Data was examined for normality according to the ShapiroWilk test. For comparison of proportions (overall morbidity, 30-day reoperations, 30-day hospital readmissions, and 30-day mortality), chi-square and Fisher's exact tests were carried out. To compare the continuous variables analyzed (amylasemia, drain amylase, intraoperative bleeding, operative time, and hospital stay), the ANOVA (Analysis of variance) test was used. The significance level adopted was $5 \%(P$-value $<0.05)$. For the execution of analysis, it was used SSPS v.16.0 software (IBM Inc., Armonk, NY, USA) for Windows version 9.2.

\section{RESULTS}

Of the 170 individuals selected for study, $150(88.2 \%)$ were female and $20(11.8 \%)$ were male. The mean age was $37.9 \pm 9.8$ years old. Mean BMI was $36.4 \pm 4.1 \mathrm{~kg} / \mathrm{m}^{2}$. The commonest comorbidities were hypertension (37.6\%) and dyslipidemia (30\%). The main characteristics of the studied individuals are detailed in TABLE 1.

Mean hospital stay was $4.5 \pm 1.3$ days. Overall morbidity was $22.9 \%$ and the commonest complication was wound infection $(6.5 \%)$. There were $21(12.3 \%) 30$-day hospital readmissions, most of them of caused by vomiting $(4.7 \%)$. There was one death $(0.6 \%)$, which was caused by sepsis secondary to a gastrojejunostomy leak. TABLE 2 shows the complete analyzed surgical

TABLE 1. Main characteristics of the studied individuals

\begin{tabular}{lc}
\hline $\mathbf{N}$ & 170 \\
\hline Age & $37.9 \pm 9.8(20-69)$ \\
Gender & \\
M & $20(11.8 \%)$ \\
F & $150(88.2 \%)$ \\
Weight $(\mathrm{kg})$ & $96.1 \pm 13.4(69-143)$ \\
BMI $\left(\mathrm{kg} / \mathrm{m}^{2}\right)$ & $36.4 \pm 4.1(35-48.3)$ \\
Comorbidity Profile & \\
Hypertension & $64(37.6 \%)$ \\
Asthma & $21(12.4 \%)$ \\
Type 2 Diabetes mellitus & $28(16.5 \%)$ \\
Dyslipidemia & $51(30 \%)$ \\
Hipothyroidism & $15(8.8 \%)$ \\
\hline
\end{tabular}

$\mathrm{N}$ : number of individuals; BMI: body mass index

TABLE 2. Overall surgical outcomes of the studied population

\begin{tabular}{lc}
\hline Operative time (minutes) & $118.1 \pm 24.3(60-240)$ \\
Intraoperative bleeding $(\mathrm{mL})$ & $178.8 \pm 89.8(100-500)$ \\
Hospital stay (days) & $4.5 \pm 1.3(4-12)$ \\
Overall Morbidity & $39(22.9 \%)$ \\
Causes of Morbidity & \\
Atelectasis & $6(3.5 \%)$ \\
Cystitis & $1(0.6 \%)$ \\
Minor wound infection & $11(6.5 \%)$ \\
Major morbidity / readmission & $21(12.3 \%)$ \\
30-day hospital readmissions & $21(12.3 \%)$ \\
Causes of hospital Readmission & \\
Vomiting & $8(4.7 \%)$ \\
Dehydration & $4(2.3 \%)$ \\
Small bowel obstruction & $4(2.3 \%)$ \\
Pneumonia & $3(1.8 \%)$ \\
Major wound infection & $1(0.6 \%)$ \\
Anastomotic leak & $1(0.6 \%)$ \\
30-day reoperations & $6(3.5 \%)$ \\
Causes of reoperations & \\
Small bowel obstruction & $4(2.3 \%)$ \\
Major wound infection & $1(0.6 \%)$ \\
Anastomotic leak & $1(0.6 \%)$ \\
30-day mortality & $1(0.6 \%) *$ \\
\hline
\end{tabular}

* Cause: Sepsis secondary to leak. 
outcomes. The sole case of leak was identified on the 5th postoperative day by means of clinical signs of sepsis (tachycardia and fever); until the previous day, she presented an otherwise uneventful outcome. A computed tomography showed indirect signs of leak and a surgical exploration was carried out, when drainage and extensive lavage of the cavity were performed along with a suture of the leak and a gastrostomy in the bypassed stomach. During the operation, the leak was identified by means of an infusion of methylene blue through a Foucher tube. The patient died 8 days later due to refractory septic shock.

The frequency of high levels of amylase in the abdominal drainage depended on the parameter adopted. When the abnormal range was considered above threefold higher than the serum levels (parameter I), there were 8 individuals who presented abnormal levels on the first postoperative day; when the cut-value of 250 IU/L (parameter II) was adopted, there were two individuals who presented abnormal levels on the first postoperative day; regardless of the cut-value adopted, there was not any individual with higher levels on the fourth postoperative day. Considering the parameter I, higher drain amylase at the first postoperative day was significantly associated with leaks (12.5\% versus $0 ; P<0.00001)$. Considering the parameter II, higher drain amylase was significantly associated with longer hospital stay ( $8 \pm 5.7$ versus $4.5 \pm 1.3$ days; $P=0.00032)$, 30 -day reoperations ( $50 \%$ versus $3 \% ; P=0.000285)$, and leaks ( $50 \%$ versus $0 ; P<0.00001)$. The complete comparison and analysis of the two cut-values evaluated are presented in TABLE 3 and TABLE 4. A flowchart of the study design and main outcomes, according to the parameter adopted, is represented in FIGURES 1A and 1B.

TABLE 3. Comparison of surgical outcomes between individuals with high and low drain amylase on the first postoperative day (considering high levels when drain amylase is above three times the serum levels)

\begin{tabular}{|c|c|c|c|}
\hline & $\begin{array}{l}\text { High drain } \\
\text { amylase }\end{array}$ & $\begin{array}{l}\text { Low drain } \\
\text { amylase }\end{array}$ & Value of $P$ \\
\hline $\mathrm{N}(\%)$ & $8(4.7 \%)$ & $162(95.3 \%)$ & N/A \\
\hline $\begin{array}{l}\text { Serum amylase } \\
\text { (IU/L) }\end{array}$ & $\begin{array}{c}82.3 \pm 24.3 \\
\text { (range. 63-100) }\end{array}$ & $\begin{array}{c}76.4 \pm 21.3 \\
\text { (range. 14-101) }\end{array}$ & 0.83425 \\
\hline $\begin{array}{l}\text { Drain amylase on } \\
\text { PO1 (IU/L) }\end{array}$ & $\begin{array}{c}696.9 \pm 1513.1 \\
\text { (range. } 109-4438)\end{array}$ & $\begin{array}{c}48.8 \pm 28.6 \\
\text { (range. } 10-187 \text { ) }\end{array}$ & $<0.00001$ \\
\hline $\begin{array}{l}\text { Drain amylase on } \\
\text { PO4 (IU/L) }\end{array}$ & $\begin{array}{c}37.9 \pm 28.6 \\
\text { (range. 13-94) }\end{array}$ & $\begin{array}{c}45.8 \pm 82.3 \\
\text { (range. } 4-130)\end{array}$ & 0.60306 \\
\hline $\begin{array}{l}\text { Intraoperative } \\
\text { bleeding }(\mathrm{mL})\end{array}$ & $\begin{array}{c}181.2 \pm 65.1 \\
\text { (range. 100-200) }\end{array}$ & $\begin{array}{c}178.6 \pm 91.3 \\
\text { (range. } 100- \\
500)\end{array}$ & 0.912354 \\
\hline $\begin{array}{l}\text { Operative time } \\
\text { (minutes) }\end{array}$ & $\begin{array}{c}113.7 \pm 20 \\
\text { (range. } 90-120 \text { ) }\end{array}$ & $\begin{array}{c}118.3 \pm 24.6 \\
\text { (range. } 60-240 \text { ) }\end{array}$ & 0.812353 \\
\hline Hospital stay & $5.5 \pm 2.8(4-10)$ & $4.5 \pm 1.1(4-12)$ & 0.70394 \\
\hline Overall morbidity & $3(37.5 \%)$ & $36(22.2 \%)$ & 0.315729 \\
\hline $\begin{array}{l}\text { 30-day } \\
\text { reoperations }\end{array}$ & $1(12.5 \%)$ & $5(3.1 \%)$ & 0.158957 \\
\hline $\begin{array}{l}\text { 30-day hospital } \\
\text { readmissions }\end{array}$ & $2(25 \%)$ & $19(11.7 \%)$ & 0.265431 \\
\hline 30-day mortality & $1(12.5 \%)$ & 0 & $<0.00001$ \\
\hline
\end{tabular}

$\mathrm{N}$ : number of individuals; PO1: first postoperative day; PO4: fourth postoperative day.
TABLE 4. Comparison of surgical outcomes between individuals with high and low drain amylase on the first postoperative day (considering high levels when drain amylase is higher than $250 \mathrm{IU} / \mathrm{L}$ )

\begin{tabular}{|c|c|c|c|}
\hline & $\begin{array}{l}\text { High drain } \\
\text { amylase }\end{array}$ & $\begin{array}{l}\text { Low drain } \\
\text { amylase }\end{array}$ & Value of $P$ \\
\hline $\mathrm{N}(\%)$ & $2(1.2 \%)$ & $168(98.8 \%)$ & N/A \\
\hline $\begin{array}{l}\text { Serum amylase } \\
\text { levels (IU/L) }\end{array}$ & $\begin{array}{c}84 \pm 6 \\
\text { (range, } 78-90)\end{array}$ & $\begin{array}{c}83.5 \pm 24.6 \\
\text { (range, 17-99) }\end{array}$ & 0.73452 \\
\hline $\begin{array}{l}\text { Drain amylase on } \\
\text { PO1 (IU/L) }\end{array}$ & $\begin{array}{c}2376 \pm 2916.1 \\
(314-4438)\end{array}$ & $\begin{array}{l}51.9 \pm 33 \\
(2-189)\end{array}$ & $<0.00001$ \\
\hline $\begin{array}{l}\text { Drain amylase on } \\
\text { PO4 (IU/L) }\end{array}$ & $55 \pm 55.1(16-94)$ & $\begin{array}{c}45.3 \pm 80.9 \\
(4-130)\end{array}$ & 0.8627 \\
\hline $\begin{array}{l}\text { Intraoperative } \\
\text { bleeding }(\mathrm{mL})\end{array}$ & $\begin{array}{c}200 \pm 0 \\
(200-200)\end{array}$ & $\begin{array}{c}178.4 \pm 90.6 \\
(100-500)\end{array}$ & 0.740560 \\
\hline $\begin{array}{l}\text { Operative time } \\
\text { (minutes) }\end{array}$ & $120 \pm 0$ & $118.1 \pm 24.5$ & 0.920464 \\
\hline Hospital stay & $8 \pm 5.7(4-12)$ & $4.5 \pm 1.3(4-12)$ & 0.000319 \\
\hline Overall morbidity & $1(50 \%)$ & $38(22.6 \%)$ & 0.359911 \\
\hline $\begin{array}{l}\text { 30-day } \\
\text { reoperations }\end{array}$ & $1(50 \%)$ & $5(3 \%)$ & 0.000285 \\
\hline $\begin{array}{l}\text { 30-day hospital } \\
\text { readmissions }\end{array}$ & $1(50 \%)$ & $20(11.9 \%)$ & 0.103598 \\
\hline 30-day mortality & $1(50 \%)$ & 0 & $<0.00001$ \\
\hline
\end{tabular}

$\mathrm{N}$ : number of individuals; PO1: first postoperative day; PO4: fourth postoperative day.

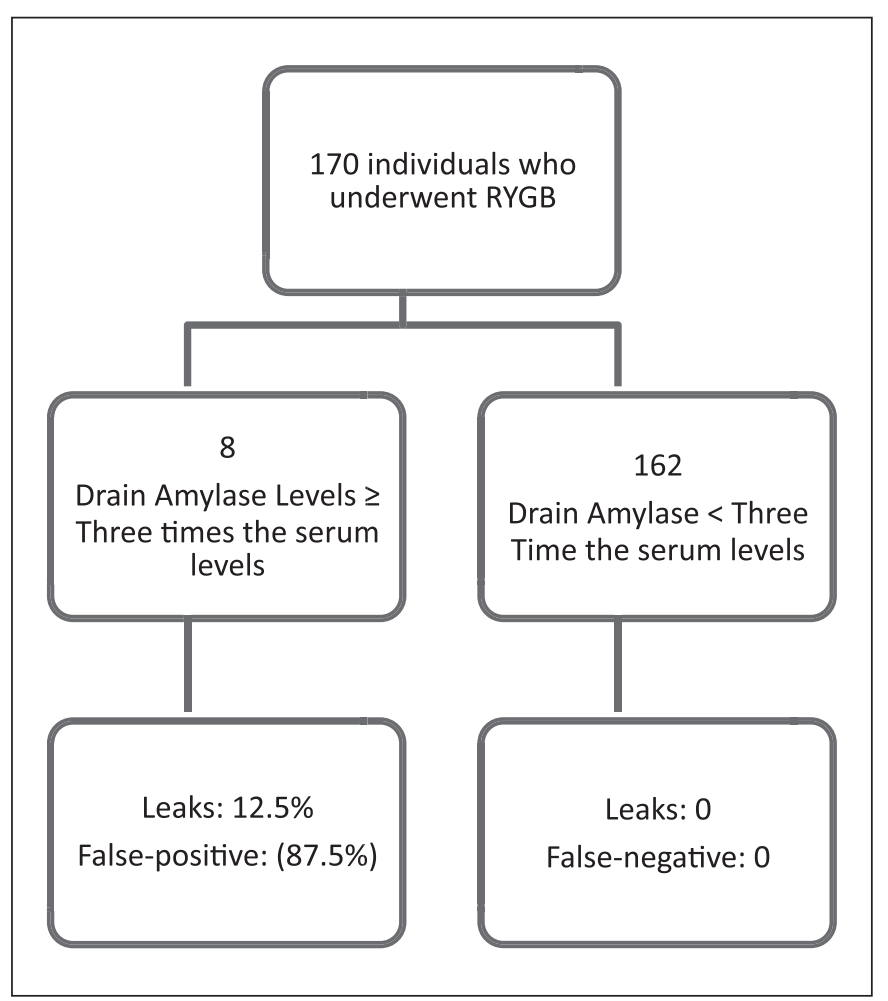

FIGURE 1A. Flowchart of the study design and significant outcomes according to the Parameter I. 


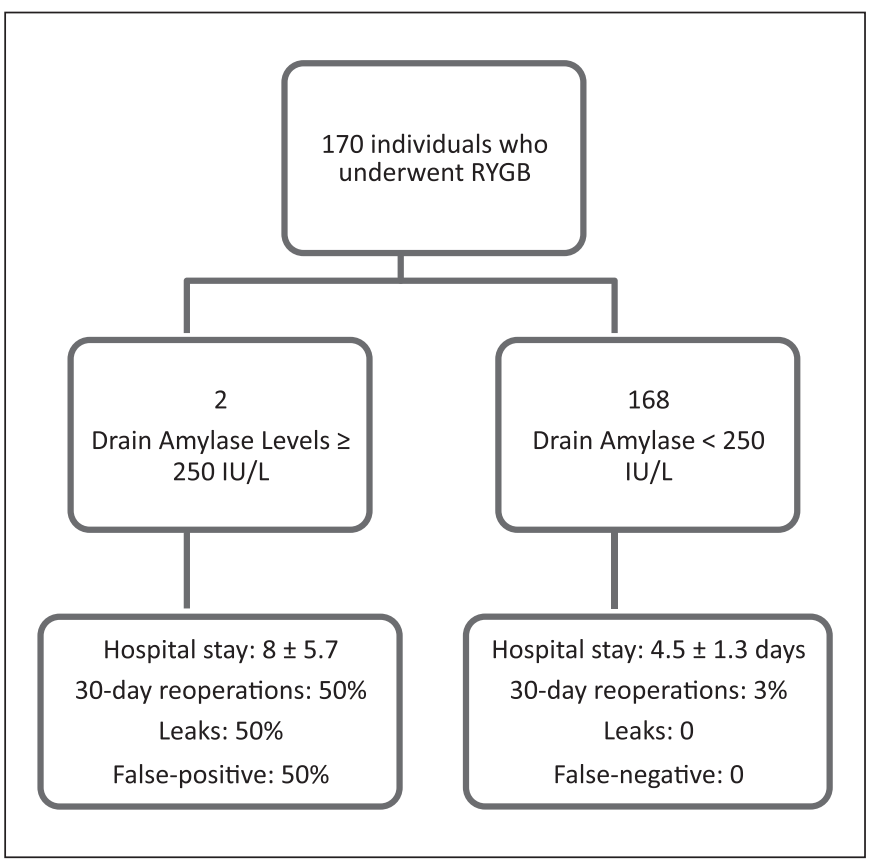

FIGURE 1B. Flowchart of the study design and significant outcomes according to the Parameter II.

No individual presented high levels of amylase in the drain on the fourth postoperative day, considering both cutoff values. Of the individuals with altered drain amylase levels considering the parameter I on the first postoperative day, only one individual presented clinical signs of sepsis and a computed tomography that showed indirect signs of a leak; the remaining seven individuals presented an uneventful postoperative course. Of the individuals with altered drain amylase levels considering the parameter II, only the same individual presented clinical signs of sepsis and a computed tomography that showed indirect signs of a leak; the remaining individual presented an uneventful postoperative course.

In regard to the diagnostic power of the levels of drain amylase to detect anastomotic leaks, the threefold higher levels' parameter on the first postoperative day presented a sensitivity of $100 \%$ and specificity of $95.9 \%$, whereas the higher than $250 \mathrm{U} / \mathrm{L}$ parameter presented a sensitivity of $100 \%$ and a specificity of $99.4 \%$. Both cutoff values of the drain amylase were highly superior to the upper gastrointestinal series and methylene blue challenges. In TABLE 5, the respective diagnostic evaluations of each test are detailed.

\section{DISCUSSION}

Gastrointestinal leaks remain a serious concern after bariatric surgery. Although their incidence has certainly decreased over time, they are still associated significant morbidity and mortality ${ }^{(8,9)}$. Anastomotic leaks and pulmonary embolism are the two most dreaded complications among patients undergoing RYGB, and considered the most common cause of death ${ }^{(12,13,14)}$. The previously reported incidence of leakage varies from $0.1 \%$ to $5.6 \%{ }^{(13,15-18)}$, which in part depends on the definition used. According to the Scandinavian Obesity Surgery Registry ${ }^{(19)}$ there is a reported leak rate of $1.4 \%$ in 19,789 women and $2.1 \%$ among 6331 men. Despite the lack of consensus, leaks are likely to be responsible for up to $30 \%$ of the overall mortality following $\operatorname{RYGB}^{(8,9,20)}$.

Furthermore, early detection of the leaks is the pinnacle for a well-succeeded treatment. However, the diagnosis may be demanding and challenging. In the present study, the radiographic study and oral methylene blue challenge were not able to detect the single case of leak; even a computed tomography scan performed when the patient which had the leak presented signs of sepsis did not show any contrast overflow through the pouch or gastrojejunostomy; only indirect signs (fat thickening, free liquid, and pneumoperitoneum) were present. The determination of amylase in the drain liquid apparently may be an inexpensive and easily available tool to help in this regard. The routine execution of an upper gastrointestinal series has revealed mixed results in the literature ${ }^{(21,22,23,24)}$. A systematic review by Quartararo et al. ${ }^{(25)}$ observed that the routine upper gastrointestinal series does not show real benefits in terms of leak detection, length of stay, and severity of complication, however the mortality rates in the series reporting the selective upper gastrointestinal series are very low and the length of stay is equal or lower than in series reporting routine upper gastrointestinal series, concluding that the selective use of postoperative radiography could be equally safe and cost-effective. The oral methylene blue challenge has been even less studied, and a recent study by Nelson et al. ${ }^{(26)}$ observed no significant differences when compared to the routine radiography.

The use of the drain amylase levels to detect leaks is based on the presence of abundant salivary amylase in the gastric juice, especially in individuals who undergo gastric resection or gastroplasty $(27)$. Under physiologic conditions, salivary amylase is denatured in the gastric $\mathrm{pH}$, but its levels within the stomach remain high for several hours ${ }^{28)}$. There are no validated cutoff values for the drain amylase. The cutoff values adopted and evalu-

TABLE 5. Accuracy of diagnostic tests evaluated to detect anastomotic leaks

\begin{tabular}{|c|c|c|c|c|c|c|}
\hline $\begin{array}{l}\text { Drain amylase higher than three times } \\
\text { the serum levels }\end{array}$ & $100 \%$ & $95.9 \%$ & 24.1 & 0 & $12.5 \%$ & $100 \%$ \\
\hline Drain amylase higher than $250 \mathrm{IU} / \mathrm{L}$ & $100 \%$ & $99.4 \%$ & 169 & 0 & $50 \%$ & $100 \%$ \\
\hline Upper gastrointestinal series & 0 & $100 \%$ & $\mathrm{~N} / \mathrm{A}$ & 1 & $\mathrm{~N} / \mathrm{A}$ & $99.4 \%$ \\
\hline
\end{tabular}

N/A: not applicable; Interpretation of Likelihood ratios: Positive likelihood ratio - > 10 (high accuracy); 5-10 (moderate accuracy); 2-5 (low accuracy); 1-2 (null accuracy); Negative likelihood ratio - < 0.1 (high accuracy); 0.1-0.2 (moderate accuracy); 0.2-0.5 (low accuracy); 0.5-1.0 (null accuracy). 
ated in this study were based in previously reported studies that investigated the influence of drain amylase in the diagnosis of fistulas following pancreatic resection ${ }^{(29,30)}$ and a proposal for the use of the drain amylase to detect leaks in varying upper gastrointestinal surgeries ${ }^{(11,31,32,33,34)}$. Since the first parameter (three times higher than the serum levels) ${ }^{(29)}$ apparently is more appropriate to pancreatic resections, it was no surprise that the other proposed parameter (higher than $250 \mathrm{IU} / \mathrm{L})^{(11)}$ showed stronger results. Maher et al. (27), using a cutoff value of $400 \mathrm{IU} / \mathrm{L}$, concluded that drain amylase levels were a simple and low-cost adjunct with high sensitivity and specificity that can help to identify patients who may have a leak after gastric bypass surgery. Nonetheless, the cutoff value adopted by that study would not detect the sole case of leak reported in the present study.

The placement of abdominal drains remains a controversial issue among bariatric surgeons. There is a tendency towards avoiding their use more recently, with evidence pointing that their use is not cost-effective and that clinical parameters such as tachycardia, fever, and increasing abdominal pain should guide further investigation for and treatment of a leak ${ }^{(35)}$. However, drain placement in selected cases may have the potential to early diagnose the occurrence of leaks ${ }^{(36)}$. The single leak case of this study illustrates this, since the amylase drain levels were increased as early as the first postoperative day, and the affected individual only presented suggestive clinical signs of leak four days later. Since there was also a false positive result, a possible use for this modality of detection would be to provide an indication for early imaging investigation, by means of computed tomography, for patients with abnormalities in the levels of amylase in the drain, but without clear clinical signs of leak. The parameter I cutoff proved to be of little validity because of its low specificity. Conversely the parameter II cutoff presented acceptable sensitivity and specificity. Since the levels of amylase in the drain raised earlier (PO 1) than the emergence of clinical signs of leak (PO 6), the use of the drain amylase levels could have provided the possibility of a more precocious diagnosis.

Despite the high accuracy of the parameter II cutoff in this study, it was far from a perfect screening test, since there was a false positive result. This individual presented a completely uneventful outcome. There are reasons that may be hypothesized to explain this false positive result: 1) overflow of gastric juice during the procedure that was not completely cleaned before abdominal closure; 2) occurrence of minor self-limited leaks without clinical significance; 3) slight pancreatic injury during the dissection of the posterior wall of the stomach. These three hypotheses also serve to explain the longer hospital stay and need for reoperations, since all of these situations may lead to the formation of intra-abdominal abscesses and peritonitis. The last hypothesis apparently are the least likely to have occurred; the possibility of pancreatic injury is yet to be clearly addressed and studied since this complication has not been previously reported to date; a possible way to confirm or discard it is to evaluate co-jointly the levels of amylase and lipase in the drain liquid. The determination of the levels on the fourth postoperative day did not result in a single abnormal result; this is likely to have been caused by the obstruction or late displacement of the drain. Nonetheless, although the statement that the drain amylase levels could be pivotal to the diagnosis, the parameter II cutoff may provide some help to determine an early imaging evaluation of individuals without any other signs of leak. This study presents some limitations that should be taken into account.
Despite the adequate sample size according to the statistical analysis, the frequency of leaks and mortality after bariatric surgery is fortunately low. Since there was a single case of leak that led to death within the group of individuals studied and the analysis for the parameter II was based on just two positive examinations, this may prevent ultimate conclusions and even the significance of the predictive value of the analyzed variable in relation to mortality should be cautiously interpreted. Furthermore, the cutoff values adopted, although previously proposed by other authors, were somewhat arbitrary. Further research, especially enrolling other high-volume bariatric centers, is necessary to confirm our findings. The standardized protocol of this service, which includes a minimum 4-day hospital stay, also may affect the hospital stay data. This protocol is due to certain specific circumstances: our service is part of the public health providing system of a middle-income country plagued by a high social inequality and, thus, the attended population presents a social, cultural, and economical background that avoids that much of the early postoperative care, that could be appropriately provided on an outpatient basis in another context, requires a longer hospital stay ${ }^{(37)}$. Also, the high rate of readmissions observed in this population is associated with this social context. The majority of the readmissions was caused by situations that, in a more favorable social context, could be perfectly managed on an outpatient basis, such as vomits and wound infections. These complications could be handled by regular consultations, simple anti-emetic medications, wound care, and oral antibiotics. However, some of these individuals do not have the possibility to access outpatient services of high quality near their homes, and most of them may not have financial conditions to afford the prescribed antibiotics.

Despite its caveats, this study has observed that the levels of drain amylase, used along clinical parameters and high degree of suspicion, could be significantly useful to indicate the possibility of longer hospital stay and reoperations, and that the cutoff value higher than $250 \mathrm{IU} / \mathrm{L}$ was the most appropriate. Hence, since it is an inexpensive and easily available lab test, it could be adopted in more bariatric centers, once it may be useful to be used along with clinical signs to early detect anastomotic leaks. Based on the present results, the selective placement of a drain in individuals undergoing RYGB may be useful to early detect leaks, and a 24-hour stay may be enough to diagnose leaks by means of the amylase levels. This approach is also likely to be useful for other surgical interventions which involve anastomoses in the upper gastrointestinal tract. Nonetheless, it is important to emphasize that, in the presence of clinical suspicion, even without any other physical, laboratory, or imaging examinations' abnormalities, the need for early surgical intervention is mandatory. The examination proposed in the current study could present significance among individuals with early leaks without other signs of this ominous complication.

\section{CONCLUSION}

The determination of drain amylase levels after RYGB was a significant indicator of leaks, hospital stay, and 30-day reoperations. This finding reinforces the importance of abdominal drainage in the RYGB within this context. In specific situations, this examination may bring relevant information for the decision-making process. Whenever, there is any suspicion of leaks, an early surgical intervention is mandatory. 


\section{Statement of human and animal rights}

All procedures performed in studies involving human participants were in accordance with the ethical standards of the institutional and/or national research committee and with the 1964 Helsinki declaration and its later amendments or comparable ethical standards.

\section{Authors' contributions}

Ribeiro IB collected the data. Gestic MA, Utrini MP, and Chaim FDM provided clinical assistance to the patients who took part in the study. Chaim EA provided relevant intellectual inserts and critical revision. Cazzo E designed the study, performed the statistical analysis and wrote the article.

Ribeiro IB, Gestic MA, Utrini MP, Chaim FDM, Chaim EA, Cazzo E. Utilização dos níveis de amilase no dreno abdominal para diagnóstico de fístulas anastomóticas após o bypass gástrico em Y de Roux. Arq Gastroenterol. 2018;55(1):66-71.

Resumo - Conteúdo - Embora a incidência de fistulas após o bypass gástrico em Y de Roux (BGRY) tenha diminuído significativamente com a evolução da técnica, sua detecção continua desafiadora. Objetivo - Determinar a acurácia dos níveis de amilase no dreno abdominal para detector fístulas após o BGYR. Métodos - Este é um estudo populacional que avaliou 170 indivíduos submetidos ao BGYR. Os níveis de amilase no dreno foram determinados no primeiro e quarto dias de pós-operatório. Dois pontos de corte foram avaliados: três vezes maior que os níveis séricos (parâmetro I) e acima de 250 UI/L (parâmetro II). Os principais desfechos estudados foram: morbidade perioperatória, ocorrência de fístulas, reinternações e reoperações nos primeiros 30 dias, permanência hospitalar e mortalidade. Resultados - Considerando o parâmetro I, altos níveis de amilase do dreno foram indicadores significativos de fístulas $(12,5 \%$ vs $0 ; P<0,00001)$. Considerando o parâmetro II, altos níveis de amilse no dreno estiveram significativamente associados a maior permanência hospitalar ( $8 \pm 5,7$ vs $4,5 \pm 1,3$ dias; $P=0,00032)$, frequência de reoperações $(50 \%$ vs $3 \% ; P=0,000285)$ e ocorrência de fístulas $(50 \%$ vs $0 ; P<0,00001)$. O parâmetro I apresentou sensibilidade de $100 \%$ e especificidade de $95,9 \%$, enquanto o parâmetro II apresentou sensibilidade de $100 \%$ e especificidade de $99,4 \%$. Conclusão - A determinação dos níveis de amilase no dreno após o BGYR foi um indicador significativo de fístulas, permanência hospitalar e reoperações. Este achado reforça a importância da drenagem abdominal no BGYR dentro deste contexto.

DESCRITORES - Obesidade. Cirurgia bariátrica. Derivação gástrica. Fístula anastomótica. Complicações pós-operatórias.

\section{REFERENCES}

1. Baltieri L, Claudio Martins L, Cazzo E, et al. Analysis of quality of life among asthmatic individuals with obesity and its relationship with pulmonary function: cross-sectional study. Sao Paulo Med J. 2017 Jul 31:0. doi: 10.1590/1516 3180.2016.0342250217

2. Cazzo E, Gestic MA, Utrini MP, et al. Influence of Insulin Resistance Status on the Development of Gallstones Following Roux-En-Y Gastric Bypass: a Prospective Cohort Study. Obes Surg. 2016;26:769-75.

3. World Health Organization. Global status report on noncommunicable diseases 2014. Geneva: WHO. 2014: 1-298.

4. Angrisani L, Santonicola A, Iovino P, et al. Bariatric Surgery and Endolumina Procedures: IFSO Worldwide Survey 2014. Obes Surg. 2017 Apr 13. doi: 10.1007/ s11695-017-2666-x.

5. Cazzo E, Callejas-Neto F, Pareja JC, et al. Correlation between post over preoperative surrogate insulin resistance indexes' ratios and reversal of metabolic syndrome after Roux-en-Y gastric bypass. Obes Surg. 2014;24:971-3.

6. Cazzo E, da Silva FP, Pareja JC, et al. Predictors for weight loss failure following Roux-en-Y gastric bypass. Arq Gastroenterol. 2014;51:328-30.

7. Cazzo E, Gestic MA, Utrini MP, et al. Control of hypertension after roux-en-y gastric bypass among obese diabetic patients. Arq Gastroenterol. 2014;51:21-4.

8. Augustin T, Aminian A, Romero-Talamás H, et al. Reoperative Surgery for Management of Early Complications After Gastric Bypass. Obes Surg. 2016;26:345-9.

9. Smith MD, Patterson E, Wahed AS, et al. Thirty-day mortality after bariatric surgery: independently adjudicated causes of death in the longitudinal assessment of bariatric surgery. Obes Surg. 2011;21:1687-92.

10. Gastrointestinal surgery for severe obesity: National Institutes of Health Consensus Development Conference Statement. Am J Clin Nutr 1992;55(2 Suppl):615S-619S.

11. Villanueva IA, Gersin KS, Norton HJ, et al. Drain Amylase Levels in Roux-en-Y Gastric Bypass: What Is a Normal Value? [Presentation at the SAGES 2008 Meeting: Surgical Spring Week; 2008 April 9-12; Philadelphia, Pennsylvania].

12. Goldfeder LB, Ren CJ, Gill JR. Fatal complications of bariatric surgery. Obes Surg. 2006;16:1050-6.

13. Jacobsen HJ, Nergard BJ, Leifsson BG, et al. Management of suspected anastomotic leak after bariatric laparoscopic Roux-en-y gastric bypass. Br J Surg. 2014;101:417-23

14. Livingston EH. Complications of bariatric surgery. Surg Clin North Am. 2005;85:853-68.

15. Fernandez AZ, Jr, DeMaria EJ, Tichansky DS, et al. Experience with over 3000 open and laparoscopic bariatric procedures: multivariate analysis of factors related to leak and resultant mortality. Surg Endosc. 2004;18:193-7.

16. Fullum TM, Aluka KJ, Turner PL. Decreasing anastomotic and staple line leaks after laparoscopic Roux-en-Y gastric bypass. Surg Endosc. 2009;23:1403-8.

17. Higa KD, Boone KB, Ho T. Complications of the laparoscopic Roux-en-Y gastric bypass: 1040 patients - what have we learned? Obes Surg. 2000;10:509-13.

18. Wittgrove AC, Clark GW. Laparoscopic gastric bypass, Roux-en-Y - 500 patients technique and results, with 3-60 month follow-up. Obes Surg. 2000;10:233-39.

19. Scandinavian Obesity Surgery Registry. Årsrapport SOReg 2011. [Internet] [Accessed 1 January 2017]. Available from: http://www.ucr.uu.se/soreg/index. php/dokument/doc_download/36-arsrapport-soreg-2011
20. Varban OA, Cassidy RB, Sheetz KH, et al. Technique or technology? Evaluating leaks after gastric bypass. Surg Obes Relat Dis. 2016;12:264-72.

21. Leslie DB, Dorman RB, Anderson J, et al. Routine upper gastrointestinal imaging is superior to clinical signs for detecting gastrojejunal leak after laparoscopic Roux-en-Y gastric bypass. J Am Coll Surg. 2012;214:208-13.

22. Madan AK, Stoecklein HH, Ternovits CA, et al. Predictive value of upper gastrointestinal studies versus clinical signs for gastrointestinal leaks after laparoscopic gastric bypass. Surg Endosc. 2007;21:194-6.

23. Schiesser M, Guber J, Wildi S, et al. Utility of routine versus selective upper gastrointestinal series to detect anastomotic leaks after laparoscopic gastric bypass. Obes Surg. 2011;21:1238-42.

24. White S, Han SH, Lewis C, et al. Selective approach to use of upper gastroesophageal imaging study after laparoscopic Roux-en-Y gastric bypass. Surg Obes Relat Dis. 2008;4:122-5.

25. Quartararo G, Facchiano E, Scaringi S, et al. Upper gastrointestinal series after Roux-en-Y gastric bypass for morbid obesity: effectiveness in leakage detection. a systematic review of the literature. Obes Surg. 2014;24:1096-101.

26. Nelson L, Moon RC, Teixeira AF, et al. Methylene Blue or Upper GI, Which is More Effective for Detecting Leaks in Gastric Bypass Patients? Surg Laparosc Endose Percutan Tech. 2015;25:451-4

27. Maher JW, Bakhos W, Nahmias N, et al. Drain amylase levels are an adjunct in detection of gastrojejunostomy leaks after Roux-en-Y gastric bypass. J Am Coll Surg. 2009;208:881-4; discussion 885-6.

28. Peyrot des Gachons C, Breslin PA. Salivary Amylase: Digestion and Metabolic Syndrome. Curr Diab Rep. 2016;16:102.

29. Bassi C, Marchegiani G, Dervenis C, et al. The 2016 update of the International Study Group (ISGPS) definition and grading of postoperative pancreatic fistula: 11 Years After. Surgery. 2016. pii: S0039-6060(16)30757-7.

30. Gestic MA, Callejas-Neto F, Chaim EA, et al. [Surgical treatment of chronic pancreatitis with frey procedure: current situation]. Arq Bras Cir Dig. 2011;24: 305-311.

31. Baker EH, Hill JS, Reames MK, et al. Drain amylase aids detection of anastomotic leak after esophagectomy. J Gastrointest Oncol. 2016;7:181-8.

32. Berkelmans GH, Kouwenhoven EA, Smeets BJ, et al. Diagnostic value of drain amylase for detecting intrathoracic leakage after esophagectomy. World J Gastroenterol. 2015;21:9118-25.

33. Perry Y, Towe CW, Kwong J, et al. Serial Drain Amylase Can Accurately Detect Anastomotic Leak After Esophagectomy and May Facilitate Early Discharge. Ann Thorac Surg. 2015;100:2041-6; discussion 2046-7.

34. Phuong V, Kuwada TS, Villanueva I, et al. What is the normal drain amylase range for laparoscopic sleeve gastrectomy? [Presentation at the SAGES 2014 Meeting: Surgical Spring Week: 2014 April 2-5; Salt Lake City, Utah].

35. Bradley DD, Garcia CG, Elizondo JD, et al. Early Detection of Leak in Non-Bariatric Foregut Surgery: The Role of Routine Postoperative Drain Amylase. [Presentation at the SAGES 2013 Meeting: Surgical Spring Week; 2013 April 17-20; Baltimore, Maryland].

36. Kavuturu S, Rogers AM, Haluck RS. Routine drain placement in Roux-en-Y gastric bypass: an expanded retrospective comparative study of 755 patients and review of the literature. Obes Surg. 2012;22:177-81.

37. Chaim EA, Pareja JC, Gestic MA et al. Preoperative multidisciplinary program for bariatric surgery: a proposal for the Brazilian Public Health System. Arq Gastroenterol. 2017;54:70-4. 